\title{
Aesthetic geometries of life
}

\section{Introduction}

In the Ethics (1677), Spinoza examines how the individual's physical and mental experiences of subjectivity are composed of 'powers' of existence. In the discussion that follows I suggest that this capacity for existence or life can also be defined as a form of aesthetic experience. Rather than delimiting aesthetic thinking to a specific classification, discipline or intellectual appreciation of beauty, Spinoza suggests that aesthetics exists in the corporeal powers of the individual and these produce her/his life: aesthetics is composed by one's capacity for selfindividuation. For Spinoza, aesthetics is simultaneously intrinsic to our corporeal or bodily experiences and in our mental powers of reasoning. Also, because these can be positive or negative experiences of subjecthood, we may also consider the text to be a study of the connections between aesthetics and the power of agency or wellbeing in the individual.

The Ethics articulates an 'aesthetics of life' through two distinct modes or relations. ${ }^{1}$ First, the geometric form is aesthetically important because Spinoza redirects this traditionally mathematical science into a mode of reasoning about distinctly passionate human experiences, especially in its study of the power of our emotions. Also, because geometry is inherently connected to the idea of ratio, that is, the relational power of reasoning, we will see that it is particularly good at showing the value of aesthetic experience for life.

Second, I suggest that Spinoza's study of the affects draws attention to the corporeal powers of constituting individuated and social life. Our affects generate the individual's capacity to 'care' for oneself and therefore to have agency over her/his wellbeing. While Spinoza does not employ a vocabulary of 'care' as it is found in much thinking about societal wellbeing today, we will see that his study of varied aesthetic experiences constitutes a theory of agency which has considerable affinity with contemporary debates about individual, and by extension, with questions of societal wellbeing.

Interestingly, Spinoza also shows that aesthetics extends beyond the human individual and society into a consideration of the natural world. Whether it is a human, an animal, or an inorganic substance, each entity's powers of existence define its specificity within its

\footnotetext{
${ }^{1}$ For further discussions of 'relations' and 'relational aesthetics' in Spinoza's philosophy see previous publications: Space, Geometry and Aesthetics: Through Kant and Towards Deleuze (Basingstoke: Palgrave Macmillan, 2008); Relational Architectural Ecologies: Architecture, Subjectivity and Nature (London: Routledge, 2013), and Poetic Biopolitics: Practices of Relation in Architecture and the Arts (London: IB Tauris, 2016). Following feminist, race and poststructuralist approaches that challenge autonomy, self-sameness and exclusion, 'relational' spatial, material, technological and ecological subjectivities are core to these texts.
} 
respective environment, and which may therefore be understood as an aesthetic relation. This attribution of aesthetic power to organic and inorganic entities (i.e. nature), means that Spinoza's aesthetics is also a theory of ecology. Below I briefly outline that his discussion of 'Substance' in the Ethics is an especially important aspect of his aesthetics for today's arts practitioners because it underpins how 'life' is not delimited to human society or actions, but extends to the wellbeing of the environment, inorganic resources, as well as to 'other' human and nonhuman (organic and inorganic) entities who are not accorded with the same 'ethical' value of existence (e.g. as found in slavery or in the exploitative extraction of natural resources).

In the final sections of the article, I show that Spinoza's aesthetics has sympathy with the cultural, environmental and political aims of contemporary arts practices which express artful political, social and environmental reasoning (e.g. architecture and 'spatial' practices, including landscape design and land art, which explicitly critique human and environmental relations). Such practices seek to extend our understanding of the aesthetic relations that construct environmental, planetary, and human subjectivity. Below I explore two examples of these visual arts from the twentieth-century: imaginary geometric drawings of the earth by the artist, Agnes Denes, and a series of world maps by the architect, Buckminster Fuller. Fuller's and Denes's planetary aesthetics have an affinity with Spinoza's thinking because they examine the geometric, social and biological power relations that constitute 'life', both positively and negatively: relations that are now clearly visible in the twentieth and twentyfirst century geopolitical crises of human-made climate change and environmental pollution. As a result, this article hopes to show that in each of these disciplines (art, architecture and philosophy), different powers of geometric reasoning construct human, technological and environmental aesthetic relations.

\section{Life}

The word 'aesthetics' does not appear in the Ethics, ${ }^{2}$ however, this text has a strong affinity with contemporary understandings of aesthetics if we consider it to be the study of the different ways or modes of expression by which we may choose to live and define ourselves. In Part 3 of the Ethics, Spinoza explains how the 'conatus', that is, the life or_existence of an individual, is composed of a specific set of powers in that person:

Therefore, the power of any thing, or the conatus with which it acts or endeavours to act, alone or in conjunction with other things, that is ..., the power or conatus by

\footnotetext{
${ }^{2}$ In philosophy, the term 'aesthetics' is attributed to Gottfried Baumgarten's 1750 essay

'Aesthetica'.
} 
which it endeavours to persist in its own being, is nothing but the given, or actual, essence of the thing. E IIIP7Proof6.

Our power of existence is constituted in the variable experiences of the self, and Spinoza pays special attention to these powers of subjectivity, which he calls the 'affects'. These are the uniquely human modes of expression through which we define ourselves, and through which we interact with the world around us; for example, the mental and physical expressions of joy in being in love or the pain of grief. In Part III, and especially in Part IV of the Ethics, Spinoza undertakes an extremely detailed study of these powers, describing the positive expression that the emotions, such as, joy, desire or delight engender in us, and the negative or passive self-identification that we can feel in hatred, jealousy, anger or melancholy. In 'Definitions of the Emotions' in Part III, for example, he observes that when our encounters are more pleasurable we can experience 'a state of greater perfection' (E III Definitions of the Emotions 1E2), but when they are painful, we are diminished by 'less perfection' (E IIIDefEE3). Interestingly, Spinoza also emphasises the inherently variable and changing nature of this passionate reasoning; for example, in E PIIIP51 different modes of subjectivity are produced in us when we are variously affected by our positive and negative experiences in the world: 'Different men can be affected in different ways by one and the same object, and one and the same man can be affected by one and the same object in different ways at different times'. Such observations are important articulations of an aesthetic theory, because they show that Spinoza does not separate affective or emotional processes of expressing selfhood from the experience of reasoning (which is traditionally considered to be a dispassionate form of scientific thinking). Instead, he deliberately draws attention to the value that the affects (and their respective emotions) have in our experiences of reasoning.

The significance which Spinoza gives to our human powers of expression (the affects) is central to his aesthetics. Rather than being relegatesd to sensible or 'non-sense' powers (as is established in eighteenth-century moral philosophy and aesthetics of taste), our affects (what I have previously called 'sense-powers' ${ }^{3}$ ) constitute legitimate agencies within our powers of reasoning: that is, our powers of aesthetic expression are not excluded from the act of reasoning. Instead, by its very nature of being a human condition, reasoning is an aesthetic experience and, for Spinoza, aesthetics is itself the ethical or artful act of reasoning. As I show in the following paragraphs, this aesthetic agency in reasoning is also important because ratio (reason) is not discrete from the sensibility, or delimited to an exclusively disembodied cognitive form of rational power. Importantly, aesthetics and rationality are mutually engaged, not mutually exclusive from each other. Rather, aesthetics is the artful

\footnotetext{
${ }^{3}$ See Rawes, Space Geometry and Aesthetics: Through Kant and Towards Deleuze (Basingstoke: Palgrave Macmillan, 2008).
} 
power of reasoning, not solely a discipline which is concerned with establishing separate or opposing categories of beauty versus ugliness, or harmony versus disorder.

\section{Geometry}

Spinoza's view that our affective life is integral to our powers of reasoning is underpinned by his use of the 'geometric' method through which he expresses his written argument. Taking the geometric style of explanation from Euclid's Elements (300BC), the Ethics is structured axiomatically in a 'geometric ordinare' manner, through which the argument is made in a series of steps or 'elements'. Following Euclid, Spinoza uses a 'practical' textual geometric form to lay out the distinct elements that compose human experience: for example, the essay begins with a series of axioms, definitions and propositions, and together with less familiar geometric 'elements', including, corollaries and scholia, Spinoza develops his analysis 'step-by-step'. ${ }^{4}$

Although geometric thinking produces singular axiomatic 'truths', Spinoza shows that these entities are also always related to processes of existence: for example, each of the individuated axioms which states what it means to be human, such as the unique singularity of our mental and physical modalities (e.g. E IIDefI), is also connected to definitions that highlight their unequivocal relationality to each other. Our mental and corporeal modes cannot exist without the other; each is the complementary object or idea of the other (e.g. E IIP12 and E IIP13).

Like the inherent relational connection between the mind and the body, Spinoza also considers mathematical and aesthetic reasoning to be related activities. The inherently relational nature of reasoning (and thereby geometry and aesthetics as specific modes of reasoning) is more explicit if we consider the Greek etymology of reason in the word ratio. In modern scientific usage, ratio is often more commonly associated with rational thinking, but if we also take ratio to mean a 'relation', then ratio defines a 'thing' (or entity) which is simultaneously also a part, or a proportion, of an other thing: for example, a triangle is an example of geometric thinking; an idea exists within a larger discourse or belief system; a person's imagination is one mode of subjectivity amongst many; or a specific plant or animal species exists within an ecosystem.

\footnotetext{
${ }^{4}$ However, the regularity and consistency of Spinoza's geometric method does break down in Parts IV and V: see Peg Rawes 'Spinoza's architectural passages and geometric comportments' in Spinoza Beyond Philosophy, edited by Beth Lord (Edinburgh: Edinburgh University Press, 2015), p. 48-65.
} 
The especially relational nature of geometry is also visible if we consider how geometric figures are written algebraically: for example, when the figure of a hypotenuse is written algebraically it is composed of different functions $\left(a^{2}+b^{2}=c^{2}\right)$. We can see that it is formed out of the difference between two states of magnitude or value. The very idea of a geometric figure itself is therefore composed of difference. Geometry then, as a particular mode of aesthetic reasoning, is shown to be inherently connected to the diversity of experience and existence, rather than a discrete mathematical or scientific discipline that is often considered to prioritise symmetrical similarity or harmony. ${ }^{5}$

Spinoza compellingly shows that these geometric relations arise because of the connection between our mental and physical experiences. Geometry is not a mathematical procedure or constitution of ideal or disembodied forms which are unknowable to the individual (i.e. the issue of the 'divided line' in Plato's theory of ideal forms, in which reason is only always/ever divine and unknowable, and thereby entirely distinct and exclusive of the sensible, yet inconsistent and frail, human subject ${ }^{6}$ ). Instead, the Ethics presents geometry as an inherently relational form of reasoning (and a distinctly human power).

In the same way, in Proof of E IPI49, Spinoza explains that a triangle is a completely individuated entity, in and of itself, yet its singularity is simultaneously evidence that it is of a geometric mode of reasoning. This simultaneous existence of individuation and relationality is also true for human experience: each person's way of living is uniquely individuated, but is also part of society. Our singular mental and physical integrity is always connected to mental and physical expressions of life in society. Later in this discussion, I explain how Spinoza considers how our feelings of joy, pain or anger have positive and negative impacts on ourselves, and on the society in which we live, but for the moment we can say that Spinoza connects geometric ratio with the production of the individual, and by extension, with societal values. He shows that our relational powers of reasoning extend from expressing the singularly unique qualities of an individuated person or entity, to the artful and scientific powers of invention, to the diversity of the natural and inorganic world. Moreover, our power to affirm our existence, and other's existence (human and otherwise),

\footnotetext{
${ }^{5}$ See, for example, Leon Battista Alberti's fifteenth-century theory of painting and architecture, and his buildings, in which geometric symmetry and harmony are considered aesthetic beauty.

${ }^{5}$ In The Republic, Book VI, 510-510e, Plato identifies two distinct realms of existence: the upper transcendental or divine realm of pure being, and the lower sensible realm of 'becoming'. For a particularly geometric analysis see, for example, Ian Mueller's introduction to Proclus's Commentary on the First Book of Euclid's Elements (410-85AD), translated by Glenn R. Morrow (Princeton: Princeton University Press 1992), p. xvii-iii. For a feminist critique see, for example, Luce Irigaray, Speculum of the Other Woman, translated by Gillian C Gill (Ithaca NY: Cornell Press, 1985), p. 243-44.
} 
means that this is a kind of relational reasoning (or, as I hope is becoming apparent here, an aesthetic form of reasoning), which connects the singular individual to the social group. Unlike modernist aesthetic theories which tend to describe the solitary or autonomous viewer, author, architect or artist, 7 Spinoza's aesthetic relations retain a connection to the social: the integrity of the individual is always constituted in relation to their respective society. Aesthetics is not excluded from the social, but is made and lives within it (and so it follows that philosophers, artists, architects, and their readers, viewers and participants, are therefore also always constructed in relation to their respective society).

\section{Substance}

As I noted above, Spinoza's aesthetics underpins the individual's capacity to care for herself, and the benefits this can bring to society, but it is also concerned with the relationship between humans and the environment. In the same way that our capacity for unique selfdetermination is possible because of the relationship between our selves (our corporeality) and others in society, our capacity for life is also connected to natural and divine powers of existence.

Spinoza emphasises this very important connection between human life and the existence of divine natural powers at the beginning of the Ethics when he discusses the relationship between man, God and Nature in the term, Substance. He writes that substance's powers are: 'that which is in itself and is conceived through itself; that is, that the conception of which does not require the conception of another thing from which it has to be formed' (E IDef3). Substance is the concept of divine nature's distinct existence, as well as the premise of human life. In addition, this definition is very similar to his explanation of the conatus, although here the individual's powers of existence are attributed both with the capacity to self-individuate and in relation to a divine Nature or Substance.

Notably, for Spinoza, human existence is not just constructed through an imitation of the divine, but in the relationship between the human and the divine (each retaining its distinct nature). Our agency, and powers of self-expression are therefore derived from the relationship between the individuated self and divine nature. In this respect, we can suggest that Spinoza presents a kind of ecological theory of social and natural relations here, in which Nature, or Substance, is an irreducible ecological power from which our specifically human powers of intellect, imagination and the emotions are produced.

\footnotetext{
${ }^{7}$ Historically, such an emphasis on singularity and exceptionalism are core concepts of 'genius' in modernist art and architecture.
} 


\section{Wellbeing and care}

In Part I of the Ethics Spinoza describes how our capacity to be affected and our subsequent sense of increased or diminished agency (wellbeing) occurs in two ways: first, through our power of imagination to generate aesthetic agreement or disagreement between our ideas and the world/nature we inhabit (E IP36S) and secondly, through the sensory stimulation of our nervous system, including the action on us from sounds, smells or tastes, which 'are conducive [or not] to our feeling of well-being' (E IP36S).

Consequently, our ability to care for ourselves (i.e. our agency or wellbeing) arises from the experience of a diverse range of relations that affect our mental and physical powers. These experiences may be derived from affirmative or negative events, and occur because of internal or external changes: for example, Spinoza observes that emotional or physical pain and discomfort both impedes the flourishing of our personal wellbeing, and diminishes society. In Part IV he writes: 'That which so disposes the human body that it can be affected in more ways, or which renders it capable for affecting external bodies in more ways, is advantageous to man, ... On the other hand, that which renders the body less capable in these respects is harmful' (E IVP38), and: 'Whatever is conducive to man's social organisation, or causes men to live in harmony, is advantageous, while those things that introduce discord into the state are bad' (E IVP40).

Our powers of self-care extend from the positive activity of laughter and love, to the negative experience of melancholy or depression, constituting an aesthetics of life that is composed of both positive and negative powers. Again, in contrast to aesthetics of beauty and harmony, which reject or exclude disorder or ugliness as 'anti-aesthetic', Spinoza's aesthetics recognises that negative experiences or states of mind are valid, and these also constitute the individual in variable intensities and durations (E IVP61 and E VP7). Our capacity to live well (to have agency and care of the self) is composed of the complex ratios of power between our human mind and body, and in the agreement or disagreement between our affects.-These transformative powers therefore compose important modalities of aesthetic life.

Interestingly, Spinoza's intensive analysis of the relational structure of these mental and physical, social and ecological (i.e. nonhuman) powers previews Foucault's biopolitical understanding of subjectivity. In his late biopolitical seminars from 1984, Michel Foucault turns from his study of inhumane social, political and economic regimes to a discussion about the 'art of living' in ancient Greek thought. Analysing texts from early seventeenthcentury France, he distinguishes between early-modern technocratic forms of management versus ancient Greek notions of care which constitute the 'art' of life; epimelesthai sautou or 
'care of yourself'. ${ }^{8}$ For the Greeks, the city is composed of the art of life, of care, rather than of knowing, connecting with contemporary ideas of 'everyday life' in architecture, urbanism and art, such as, Michel de Certeau, The Practice of Everyday Life (1980), Dell Upton, 'Architecture in everyday life' (2002), or Doina Petrescu, Altering Practices: Feminist Politics and Poetics of Space (2007). ${ }^{9}$

Foucault also observes that societies are characterised by 'the type of rationality in which they are rooted.' This suggestion that different kinds of reasoning may exist which are not determined by governmentality or technocratic control provides an important point of connection between twentieth-century political philosophy and the artful powers of the Ethics, especially the role of ratio as an aesthetic power: in each philosophy, the subject's, and society's agency is produced because of the power of the individual to care for him/herself.

Spinoza's early-enlightenment 'artful' care of the self precedes Foucault's twentieth-century critique of inhumane reason. The Ethics shows that our corporeal powers represent a humane kind of rational (i.e. geometric) and artful care of the self, not the governmental biopowers which Foucault observes subjugate and manage the individual. Instead, as a technology of self-care (rather than of technocratic management) Spinoza's aesthetics resonate strongly with calls for advanced capitalist societies to improve their provision of housing, health and environmental needs through ethics of 'care' and social responsibility. Recently, these debates about the decline in management and maintenance of social housing, and the need for improved social care and responsibility, have been heightened in the UK, following the tragic fire and loss of life in Grenfell Tower in the West London borough of Kensington and Chelsea.

Questions about 'care of the self' are also leading concerns for visual arts practitioners for whom aesthetics is a concern in the formation of cultural, societal, economic, political and environmental ethics. Contemporary artists, designers and philosophers, such as, Hélène Frichot, Stephen Loo, Julieanne Preston, Mary Rawlinson, Jane Rendell and Undine Sellbach, share in the view that subjectivity and society are not best defined by concepts of equality and law based upon notions of homogenous moral equivalence. ${ }^{10}$

\footnotetext{
${ }^{8}$ Luther Martin, Huck Gutman, Patrick Hutton, Technologies of the Self: A seminar with Michel Foucault (Amherst MA: University of Massachusetts Press, 1988), p.19.

${ }^{9}$ Michel de Certeau, The Practice of Everyday Life, translated by Steve Randall (Berkeley: University of California Press, 1984); Dell Upton, 'Architecture in everyday life', New Literary History (John Hopkins University Press, Volume 33, Number 4, Autumn 2002), 707-723; Doina Petrescu (ed.), Altering Practices: Feminist Politics and Poetics of Space (London: Routledge, 2007).

${ }^{10}$ See, for example, work by these practitioners in Rawes et al., Poetic Biopolitics (2016).
} 
But aesthetics - as a form of care of the self - also raises questions about the role of visual languages of scientific diagrams, geometric projections and population studies used to manage and design individual and societal wellbeing. Below, we see that Buckminster Fuller's energy slave maps are fascinating twentieth-century visual rationalisations, but they also express troubling sociopolitical aspects of human life, environmental sustainability and advanced industrialised energy provision; especially because they show how rational and aesthetic expressions of life may be detrimental to environmental and political agency, and to flourishing individual, societal and planetary wellbeing.

Denes's 1970s map projections, and Buckminster Fuller's 1940s Dymaxion energy slave maps are also attuned to questions of human and nonhuman life. Given our deeply conflicted societal relations with the environment, these historical and environmental works are, once again, insightful aesthetic encounters. In contrasting ways, Denes and Fuller show how aesthetic geometries are composed of planetary, regional, economic and socio-political relations: for example, Denes's playful distortions of the earth's continents into organic or geometric figures; or Fuller's universal 'ecological patterns' of global human and automated energy distribution and consumption. Importantly, however, when interpreted with Spinoza's aesthetic in mind, Denes and Fuller's work is not reducible to merely beautiful visual arts or dispassionate scientific objects. Rather, these aesthetic geometries express the capacity of our sense-powers to construct, and in the case of Buckminster Fuller's energy maps, to damage, planetary, environmental and human life.

\section{Alien projections}

Figure 1: Agnes Denes, The Egg _ awaiting correct caption text.

Environmental artist, Agnes Denes's map series, 'Isometric Systems in Isotropic Space: Map Projections' (1974-6), reimagine the earth as various geometric and organic objects. ${ }^{11}$ The spherical geometry of the planet is reconfigured into other geometric figures, such as a pyramid, cube, dodecahedron, cylinder, ellipsoid, ovoid or toroid. However, each mathematically rational drawing of the earth is also given an organic name, so that an ovoid is a lemon; an ellipsoid is an egg; a ring torus is a doughnut; a helical toroid is a snail; a cylinder is a hot dog.

\footnotetext{
${ }^{11}$ Agnes Denes's book of these maps, Isometric Systems in Isotropic Space: Map Projections (from the Study of Distortions Series, 1973-1979) (Rochester: New York, Visual Studies Workshop Press and New York State Council on the Arts, 1979), can be accessed online at http://www.artistsbooksonline.org/works/mpjs.xml. Accessed 15 April 2018.
} 
By virtue of imaginatively renaming artefacts, familiar mathematical objects are given new aesthetic and cultural valency. Each projection distorts our standard perception of the classification of objects into human, organic and planetary orders of meaning. Denes herself calls the maps 'alien', ${ }^{12}$ underlining their nonstandard (nonhuman) status. These are earths which embody multiple modes of alterity because of the defamiliarisation between the entirely common-place food/object and the scientific/geometric. Technical and rational understandings of the planet are simultaneously visualised at the scale of everyday food or organic entities, each redefining its geometry into an-other mode of social and aesthetic individuation.

Denes's alien projections recalibrate the relationship between scientific and ecological definitions of life in the decade after the NASA's 1968 'earthrise' photograph, the publication of Stuart Brand's Whole Earth Catalogue, and the political environmental movements of the $1960 s,{ }^{13}$ which signalled the shift in human and planetary relations from speculative images of the planet to contested technological mappings of human and environmental phenomena. Also in 1968, Denes described her practice as 'eco-logical'14 through which she sought to critique damaging rationalist logics of resource depletion. Again, her creative alignment of scientific reasoning and environmental imagination results in a geometric aesthetics in which the figure of the earth oscillates between the planetary and the local. Denes presents both a unified and highly individuated relational ontology in which modern food commodities, globalization and planetary relations are put in direct contact with each other and in a manner that is consistent with her later, more explicit critique of global trade relations in Wheatfield: A Confrontation (1982). This 'amber field' in Manhattan's Battery Park, in front of the Twin Towers and next to the city's Financial District, foregrounds some of the negative economic relations that construct and connect twentieth century urbanism, trade and agriculture. ${ }^{15}$

As such, Denes's cosmological aesthetics constitute richly imbricated social, scientific and environmental expressions of human and planetary life. They are also in kind with other scientific, political and aesthetic ecologies of the twentieth and twenty-first centuries, such as: Rachel Carson's Silent Spring (1962); Gregory Bateson's post-war cybernetic anthropology 'ecology of mind'; Felix Guattari's The Three Ecologies (1989) and Donna Haraway's When Species Meet (2007). In each case, reasoning is a technical and aesthetic practice of care.

\footnotetext{
${ }^{12}$ Agnes Denes, 'Notes on eco-logic: environmental artwork, visual philosophy and global perspective', in special issue: 'Art and Social Consciousness' (Leonardo, 1993, 26, 5, 387-95), p.387.

${ }^{13}$ See, for example, Felicity Scott, Outlaw Territories: Environments of Insecurity/Architectures of Counterinsurgency (Harvard Mass.: MIT Press, 2016).

${ }^{14}$ Denes, ibid.

${ }^{15}$ Denes, ibid. p.389.
} 
According to these ecological aesthetics, there is an emphasis on the individuation of relations between the human and nonhuman to produce a 'cosmopolitics' of care for the self and living-with-others. Denes and these other practitioners remain important historical exemplars for contemporary visual artists who now critique our reliance on fossil-fuel on the planet's climate and geological structures.

\section{Anxious projections}

Figure 2: Buckminster Fuller, Conservation of resources, reproduced in Herbert Bayer and Container Corporation of America, World Geo-graphic Atlas, A composite of Man's Environment, Chicago, 1953, p.278. Courtesy, The Estate of R. Buckminster Fuller awaiting final caption text from BF Estate. Copyright ....

Buckminster Fuller's world energy maps from the 1940s and 1950s present historical rational visualizations of global energy use. ${ }^{16}$ These geometric projections are a particular series of designs from Fuller's large body of work that included mathematical, engineering, sociological and architectural projects, called '4D Energetic Geometry' or 'Dymaxion' designs, and produced during his extensive career between the 1920s-1970s.

Patented for Fuller in 1929 by Waldo Warren, the advertising specialist from the Marshall Field organization, the term 'Dymaxion' synthesised the words, 'dynamism,' 'maximum,' and 'ions' and was intended to codify the rational universality of his thinking. ${ }^{17}$ In contrast to the 3-dimensional geometries of Denes's maps, but like the well-known Robinson and Mercator cartographies, the Dymaxion map was a single projection view. Fuller, however, also criticised these projections for their spatial distortion of the continents (especially at the poles) and their logics of 'disassociated, remote, self-interest' which, he argued, reproduced the 'political concept of its got to be you or me; there is not enough for both.'18

The Dymaxion projection therefore conceptualised the world as a single 'comprehensive viewpoint' which Fuller proposed would enable strategic global design and management of

\footnotetext{
${ }^{16}$ For a more extended version of this discussion, see Peg Rawes, 'Insecure predictions', Structural Instability, E-flux Architecture, 24 July 2018: https://www.eflux.com/architecture/structural-instability/208706/insecure-predictions/. Accessed 28 July 2018.

${ }^{17}$ Buckminster Fuller and Robert Marks, The Dymaxion World of Buckminster Fuller (New York: Anchor Press and Doubleday Books, 1973), p.21.

${ }^{18}$ Buckminster Fuller Institute, https://www.bfi.org/about-fuller/big-ideas/dymaxionworld/dymaxion-map, accessed 15 April 2018.
} 
resources. ${ }^{19}$ However, in contrast to his utopian sustainable housing and car designs of the 1920s and 30s, these later world energy maps show the impact of international ideological, global and political cold war anxiety between the US, Germany and the Soviet Union. Directed particularly towards addressing concerns about the security of mechanised energy provision, these anxieties are most strongly captured in his figuration of energy as 'energy slaves'; human silhouettes which represent the industry of human labour (life) and mechanized labour (non-life). Intended as positive metaphors of mechanised technology that could solve the energy crisis, these human figures in fact highlight the significance of negative expressions of life (i.e. the threat to the US ideology from fascism and communism) which actively informed rational and scientific thinking at the time.

Published in 1953, the world energy map titled, 'Conservation of resources,' is an especially clear example of how positive and negative biopowers are defined, depending upon an individual's racial, social, historical and political position. ${ }^{20}$ The map shows the global distribution of energy required for meeting the actual and predicted demands for industrialized energy in the mid-twentieth century. ${ }^{21}$ Distributed across the continents, groups of human silhouettes in lines populate the different countries. ${ }^{22}$ These are 'energy slaves', units of automated or machinic energy that support industrialised development.

Each group of silhouette figures is connected to a large square made up of dots, which show the quantities of energy slaves attributed to each continent more clearly in different scales. The largest allocation is to North America, the next largest quantity is attributed to Europe, the African and Mediterranean countries, followed by Asia and South America jointly, and finally Central America, which receives zero allocation. Underneath the map a graph explains the exact calculations of energy distribution and consumption, showing how many energy slaves are required to meet the continent's mechanized energy requirements: $2774 \%$ of the global energy slaves are allocated to the US; 646\% in Europe, $152 \%$ by Africa and the Mediterranean; $114 \%$ in South America, and to Asia (which includes Australasia), and zero to Central America.

The map, and its geometric and numerical figures, displays the ideological concentration of industrialised resources to the global north, especially the US which, because of cold war

\footnotetext{
${ }^{19}$ Fuller and Marks, p.51.

${ }^{20}$ Also see Daniel Barber, 'Hubbert's Peak, Eneropa and the Visualization of Renewable Energy', in Places Journal, 20 May 2013. https://placesjournal.org/ . Accessed 15 April 2018. ${ }^{21}$ See a black and white version of the map in Fuller and Marks, p.154.

22 Peder Anker observes that the human figures in the 'Conservation of resources' map are a feature of Herbert Bayer's design graphics (see Peder Anker, 'Graphic Language: Herbert Bayer's Environmental Design,' Environmental History, 12, April 2007, p254-78). However, this synthesis of Bayer's graphics into Fuller's map also constitutes a visual language of 'energy slaves' which is consistent with Fuller's universal humanist approach.
} 
ideology of the time, also implies a consistency with the US's claims for democratic freedom. But Fuller's figures are also unsettling because they so closely align human labour with automation. Given advanced capitalist societies' historical formation through colonialism and slavery, the silhouettes-especially when they are black, as in the 1973 reprint of the map - reinforce this negative historical connection between labouring bodies and enslavement. Yet, in Fuller's maps, human life is presented as undifferentiated and interchangeable with units of robotic energy. His utopic calculations of mechanized labour for securing global post-war energy needs reveals that his aesthetics is determined by a belief in the dispassionate neutrality of scientific rationalism. However, his visual vocabulary of the human silhouettes retains the deeply negative connotations of slavery, emphasising these colonial inequalities even more strongly by its attempt to neutralize them to quantifiable geometric ratios. Despite his humanitarian vision, Fuller's dynamic universal cartography of life and energy ironically contains within it the power to dehumanize lives.

The world energy maps therefore show the inequality of distribution between 'free' and advanced industrialized (i.e. 'automated') populations, and the 'enslaved' populations of lesser industrialized continents. As such, Fuller's planetary aesthetics highlights the intense historical climate of political and energy insecurity before, during, and after World War II. Its scientific and rational visualizations encode twentieth-century US ideological and socioeconomic anxieties about sustaining 'peaceful', 'free' and profitable global markets.

Given contemporary concerns about the lack of human, financial and environmental ethical governance which continue to define our global reliance on fossil fuel extraction industries, inequalities in labour markets, and the financialisation of biometric data by governments and corporations (including the digital platforms and pharmaceutical companies) for global social, health and education markets, Fuller's complex historical designs nevertheless still have a strong aesthetic valency. Rather than being neutral sociological or scientific data visualisations, their ideological constructions about the benefit of an accelerated energy consumption and production that prioritise the US and Global North, are still issues that are passionately interrogated today. The maps connect with intense contemporary debates about the power of forecasting climate change, the planet's resources and our future wellbeing, where different ecological, political, and economic interest groups are brought into conflict with each other. As we see here, and as Lorraine Code has shown in her critique of 'mastery' and the pernicious use of cultural ignorance (agnotology) in climate change scepticism, forecasting is not a neutral form of scientific reason, but is used to promote positive and negative power relations at multiple scales. ${ }^{23}$ Scientific visualisations are then, in themselves,

\footnotetext{
${ }^{23}$ See Lorraine Code, "'Manufactured uncertainty": epistemologies of master and the ecological imaginary', in Peg Rawes (ed.), Relational Architectural Ecologies (London; New York: Routledge, 2013).
} 
sites of disagreement and contest: for example, between climate scientists and environmentalists, versus climate change deniers, corporations and governments who seek to protect fossil fuel markets and industries.

Reading these energy maps in conjunction with Spinoza's aesthetics highlights how 'sociological' designs are imbricated with biological and political powers. Fuller's slave maps show how rationalism is indeed a form of aesthetic reasoning, rather than a neutral science. Anxiety and fear about the cold war and post-war energy provision produce Fuller's aesthetic reasoning, unfortunately reinforcing the negative modes of power which he hoped to positively address. In this complex historical setting of the war we can see that aesthetics is then not a science that divides experience into clearly distinct domains of beauty or disorder, but is a much more agitated, unsettled and dynamic set of relations, in which multiple modes of activity and passivity are manifest at the same time.

Also, the maps' reflection of nineteenth and twentieth-century slavery and the protection of markets, trade and automation for advanced industrialised nations, highlights how, historically, human relations are imbricated with complex global and colonial power relations. These issues continue to be of serious concern today; from questions about affordable access to secure energy supplies, automation in the home and in the healthcare professions, to trafficking of vulnerable and migrant communities as slave labour in agriculture and domestic labour markets. Like Spinoza's analysis of the variable positive and negative energies that construct biopower, Fuller's analysis of life and nonlife (automated or enslaved) also maps out power relations which may enhance wellbeing for some recipients but which can also diminish agency in others.

Thus, by considering Denes and Fuller's geometric aesthetics in conjunction with Spinoza's aesthetics, we find that the representation of bodies and planets in these maps are not just dispassionate geometric visualisations of unchanging or discrete objects and worlds. In a similar manner to Spinoza's philosophy, Denes's drawings and Fuller's designs show how different mental and physical relations produce different degrees of wellbeing and agency in individuals, societies and worlds. In each work its geometric aesthetic emphasises the complexity of how corporeal powers or relations (ratio) construct human, societal, environmental and planetary life.

\section{BIBLIOGRAPHY}

Barber, B., 'Hubbert's Peak, Eneropa and the Visualization of Renewable Energy', in Places Journal, 20 May 2013. https://placesjournal.org/. Accessed 15 April 2018.

Bayer, H., and Container Corporation of America, World Geo-graphic Atlas, A composite of Man's Environment, Chicago, 1953. 
Buckminster Fuller Institute, https://www.bfi.org/about-fuller/big-ideas/dymaxionworld/dymaxion-map, accessed 15 April 2018.

de Certeau, M., The Practice of Everyday Life, translated by Steve Randall (Berkeley: University of California Press, 1984).

Code, L., "'Manufactured uncertainty": epistemologies of master and the ecological imaginary', in Rawes, P. (ed.), Relational Architectural Ecologies (London; New York: Routledge, 2013).

Denes, A., 'Notes on eco-logic: environmental artwork, visual philosophy and global perspective', in special issue: 'Art and Social Consciousness', Leonardo (26, 5, 387-95, 1993). Denes, A., Isometric Systems in Isotropic Space: Map Projections (from the Study of Distortions Series, 1973-1979) (Rochester: New York, Visual Studies Workshop Press and New York State Council on the Arts, 1979).

Fuller, R. B. and Marks, R., The Dymaxion World of Buckminster Fuller (New York: Anchor Press and Doubleday Books, 1973).

Irigaray, L., Speculum of the Other Woman, translated by Gillian C Gill (Ithaca NY: Cornell Press, 1985).

Lord, B., (ed), Spinoza Beyond Philosophy (Edinburgh: Edinburgh University Press, 2015). Martin, L., Gutman, H., and Hutton, P., (eds), Technologies of the Self: A Seminar with Michel Foucault (University of Massachusetts Press: Amherst MA, 1988).

Petrescu, D., (ed.), Altering Practices: Feminist Politics and Poetics of Space (London: Routledge, 2007).

Proclus, Commentary on the First Book of Euclid's Elements, translated by Glenn R. Morrow (Princeton: Princeton University Press 1992).

Rawes, P., Space Geometry and Aesthetics: Through Kant and Towards Deleuze (Basingstoke: Palgrave Macmillan, 2008).

Rawes, P., (ed), Relational Architectural Ecologies: Architecture, Subjectivity and Nature (London: Routledge, 2013).

Rawes, P., 'Spinoza's architectural passages and geometric comportments', in B. Lord (ed), Spinoza Beyond Philosophy (Edinburgh: Edinburgh University Press, 2015).

Rawes, P., 'Insecure predictions', Structural Instability, E-flux Architecture (https://www.eflux.com/architecture/structural-instability/208706/insecure-predictions/, 24 July 2018). Accessed 28 July 2018.

Rawes, P., Mathews, T. and Loo, S., (eds), Poetic Biopolitics: Relational Practices in Architecture and the Arts (London: IB Tauris, 2016).

Scott F. D., Outlaw Territories: Environments of Insecurity/Architectures of Counterinsurgency (Harvard Mass.: MIT Press, 2016).

Spinoza, B., Ethics, Treatise on the Emendation of the Intellect and Selected Letters, trans. Samuel Shirley, ed. S. Feldman (Indianapolis: Hackett Publishing Company, 1992).

Upton, D., 'Architecture in everyday life', New Literary History (John Hopkins University Press, Volume 33, Number 4, Autumn 2002), 707-723. 
Bio:

Peg Rawes is Professor of Architecture and Philosophy, and Director of the Masters in Architectural History at the Bartlett School of Architecture, UCL, London. Her research focuses on social and architectural histories of wellbeing, especially in

contemporary housing, ecologies and poetics. Publications include the film, Equal by Design (co-author with Beth Lord, 2016), and 'Housing Biopolitics and Care', in Critical and Clinical Cartographies (2017). Her edited volumes, Poetic Biopolitics: Practices of Relation in Architecture and the Arts (co-ed., 2016) and Relational Architectural Ecologies (ed., 2013) have published architects alongside practitioners in the arts, environmental and human rights, social and medical research. 